\title{
INTRODUCTION TO THE ISSUE
}

What do families need most as they involve themselves with the vocational rehabilitation system? What do rehabilitation counselors need most as they interact with families? What do researchers know about families and rehabilitation systems, and what difference does their knowledge make? These are questions to which you will find some answers in the articles in this issue.

Unless you read between the lines, however, you may miss some of the questions and answers that we think are so important. So, a word or two on what is "between the lines," together with a word or two about the printed text.

Here's one question that has come up repeatedly as we perform the multiple roles of parent of a 25-year-old who has multiple developmental disabilities, researchers and trainers at the nation's only rehabilitation research and training center focusing exclusively on families, and founders and directors of a community-based service-delivery program: Is there a "new paradigm," a new archetype that affects families, people with disabilities, providers, and researchers in all rehabilitation arenas? Answer: Yes. It's "pervasive participation."

You won't find it referred to that way in the 1992 Amendments to the Rehabilitation Act, or nearly anywhere else for that matter. Yet, the concept abounds.

What is "pervasive participation" and how does this issue of the Journal of Vocational Rehabilitation surface the concept and address it?

The authors advocate it: Consumers of rehabilitation services, research, and training activities have to be involved in developing, implementing, disseminating, and evaluating those activities, from the "git go."

They explain it: Consumer participation means that the person with a disability and the family, where appropriate, will participate at the system level and individual service-delivery levels.

The articles by Montes and Sayeed (about Fiesta Educativa in Chicago) and Stineman et al. (about the Bridges to Success project in Lawrence, Kansas) will give you some ideas about systemand individual-level consumer participation. State Director Yancey underscores the collegiality point in his lead article, and Susanne Bruyère shows how participatory action research can be useful to families, researchers, and providers.

In short, "pervasive participation" means that consumers and providers will engage with each other at the system and individual level.

They extend it: "Pervasive participation" means a good deal more than that kind of consumer participation. It also means that researchers must involve consumers and providers in the research process.

The Manns deplore the fact that institutions of higher education have not made a greater difference for their daughter, especially in her own home town. They would welcome participation with researchers (and indeed they do as directors of Full Citizenship, Inc.).

Ferguson et al. and Irvin et al. - all researchers - address "pervasive participation" in different ways. Ferguson et al. write about the "triangles" of interaction between providers, families, and individuals with disabilities and make it clear that, for researchers to understand those interactions, researchers have to involve the researched in setting the research agenda. Irvin et al. say that there is no obvious meaning of "transition" and "adult status" in the literature; if that does not suggest that researchers should ask providers and families and individuals what they think is important in defining those terms, nothing will.

What does it mean to be an "adult"? Clearly, it is at least achieving the age of majority, some economic self-sufficiency, some decision-making capacity and rights, some sense of control over one's life, a social conscience, and a sense of duty to others. It means "owning" one's life.

But what about the person with a disability, especially one who has a cognitive limitation? Does it mean the same thing for that person as it may mean for others who do not have the same limitation?

It does, and it is hard, so hard, to achieve. But it is achievable!

Just read what Madeleine Will writes. Her message is the first written one she has given since resigning as Assistant Secretary of Education and the Chief Federal Officer of Special Education and Rehabilitative Services (including the National Institute of Disability and Rehabilitation Re-

$J$ Vocat Rehabil 1993; 3(2):2-4

Copyright (C) 1993 by Andover Medical 
search) and is remarkable for its directness and challenge.

Autonomy and adult status mean that her son Jonathan will have to be his "own person," with his own dreams, own experiences, and own life. He will not be just a client whose disability needs to be remediated. To be an adult, Jonathan must come to understand himself and communicate that innate and worthy sense of self to others. That means that others will have to hear, heed, and honor that self.

A daunting challenge? Yes, of course. But then read what the Pettitts write about their daughter Michelle. Read it carefully, because you won't find too much about how systems helped Michelle. What you will find instead is the powerful influence of older sisters, the dogged determination of Michelle herself, and her parents' willingness to do whatever it takes, for however long it takes, to honor Michelle's sense of self. For your benefit today and tomorrow, you'll find some awfully good tips, too.

Talking about tips brings us to another "between the lines" message. It is this, however much we hate to admit it:

- Professionals are necessary but not sufficient

- Families are necessary but not sufficient

- Friends are necessary but not sufficient

So, you may ask, what is both necessary and sufficient to help achieve "pervasive partnership" and "adult status and autonomy"? The answer, according to Jamison, Santelli et al., and Montes and Sayeed, is this: When professionals, family, and friends combine, there's an exponential increase of power. In brief, empowerment is proportional to partnership!

Jamison writes about "shared risk" and "shared reward." She also illustrates "shared responsibility" and gives tips for sharing between professional, family, and friends.

Santelli et al. argue that the highly successful "Parent-to-Parent" model of support is urgently useful for the transition and adult-status years.

If you tend to doubt them, perhaps because they represent only two types of partnership programs, or perhaps because a researcher did not discover that empowerment is proportional to partnership, then consult Ferguson et al. and Irvin et al. and their message (explicit in the former, implicit in the latter) that partnership empowers.

SEPT/TA project is a mediating structure: a parent-directed transition-oriented effort. Fiesta Educativa is a mediating structure: a communityaction advocacy organization that has made a difference for professionals, families, and people with disabilities. Parent-to-Parent is a mediating structure: a careful matching of people who have "been there" and those who are "going there" via an organization made up of both. Bridges to Success is a mediating structure: not a provider organization, not a consumer association, but a combination that fits interstitially into the community and helps providers, families, people with disabilities, and the community alike.

What have we found useful as our son Jay (lowmoderate mental retardation, autism, and sporadic bipolar emotional mood swings) left special education and the "sheltered" system and entered, persevered in, and succeeded in community participation and "supported living"?

We found that "adult status and autonomy" has to be defined by Jay, in his own terms, not ours. Jay is a superb self-advocate. By words and behavior, not all of it without its challenges, he let us know where he wants to live and work, and who he wants as friends. Like Michelle Pettitt, he knew what he wanted and how to get our attention. Like Michelle's parents and Madeleine Will, we heard, heeded, and honored his choices.

Today, Jay lives in his own home: earns almost all of the money necessary to pay for principal, interest, taxes, and insurance on his home; has two roommates who do not have disabilities; socializes more in the nondisability world than the sheltered world; and works in competitive employment with the support of a job coach and other coworkers. He couldn't be happier with his life. Even temporary and short-term reversions to his pre-adult life, such as extended visits to our home, are clearly just tolerable, nothing more. That is not to say that he has "moved out and away," just that he prefers his adult activities to some of his pre-adult ones.

We also found that we needed the "pervasive 
partnership" of professionals (Jay's teachers and job coach), family (Jay's younger sisters' support and constructive critiques), friends (Jay's Circle of Friends), and researchers (whose work taught us a lot about how to do what we have done). None of us alone could help Jay "get a life."

Finally, we created our own "mediating structure," our own "empowerment partnership." Early on, it took the form of a Circle of Friends - family, friends, and professionals, who surrounded Jay to support his choices. After a while, it evolved into a group action planning (GAP) team. This GAP team, and the GAP process, were different from the Circle in two respects. (That is a lesson we learned by doing service delivery at Full Citizenship, not just researching in a university, and by living in the crucible of disability.)

First, it was deliberately targeted on planning, carrying out a plan, and "monitoring" or evaluating it by peer review within the GAP group. In short, it was a "shared responsibility/risk/benefit" approach - the kind Sharman Jamison describes. Second, it was a support circle for all of us, not just for Jay. When one of the GAP group needed something, the others were there to help. When a roommate needed letters of reference or time away, others wrote the letters and performed roommate duties. When a provider needed a change in a system, the group advocated for it and helped secure it.

Yet a great deal more was present in this selfcreated mediating structure. That other element was (and still is) synergy, "combined action" (first preferred definition, Webster's Ninth New Collegiate Dictionary).

Think of combined as, "to bring into such close relationship as to obscure individual characters" (first preferred definition, Webster's Ninth New Collegiate Dictionary).
Think of action as, "the bringing about of an alteration by force or through a natural agency" (second preferred definition, Webster's Ninth New Collegiate Dictionary).

What are "synergy" and "combined action" in real-life terms, in terms of Jay's "getting a life"? It is simply this: Through thick and thin, good times and hard times, we all "hung together," rehearing Jay's messages when we were inclined to take control of his life, renewing our determination when we faltered, rededicating ourselves to Jay's "get a life" mission when he was the most challenging, and repeating the celebratory refrains, "We did it, by heavens, we did it" when Jay's dreams came true.

Is any of this useful for the rehabilitation practitioner? Most certainly it is. Nearly every family and individual with a disability can engage in pervasive participation. So can most practitioners and researchers. Nearly every family and individual has a sense of self, a sense of what adult status and autonomy mean. It's a sense that practitioners had best honor if they want to be truly successful.

And practically every family and individual can link up with or even create a mediating structure, a Circle of Friends that becomes a GAP team. It's a strategy that practitioners can help advance and that we at the Beach Center and Full Citizenship, Inc., are learning to do better.

Rehabilitation policies, regulations, training, and practices most surely will have to change, and they will.

The message of pervasive participation, autonomy and adult status, and mediating structures justifies the change.

In this issue, the message finds its voice and the voice has its libretto.

H. Rutherford Turnbull III, LLM

Ann P. Turnbull, EdD 